\title{
A Study on the Flow Characteristics and Pressure Distribution of Smart Grid Air Compressors
}

\author{
Jae-Hwan Son ${ }^{1}$, Dong-Hyun $\mathrm{Cho}^{2}$, Jung-Hoon Lee ${ }^{3}$, Ho-Chul Shin ${ }^{3}$, Sung-Hoon \\ $\mathrm{Lee}^{3}$ and Min-Young $\mathrm{Ryu}^{3}$ \\ ${ }^{1}$ Daegu Mechatronics \& Materials Institute (DMI), South KOREA \\ ${ }^{2}$ Dept. of Computer Aided Mechanical Design Enginering, Daejin University, \\ South KOREA \\ ${ }^{3}$ Kunyoung Machinery Co., LTD, South KOREA \\ chodh@daejin.ac.kr
}

\begin{abstract}
The studies of redundant actuator \& smart grid high efficiency air compressors are acutely required to supply products engrafted with smart grid IT technology to inform the electric power consumed by air compressors to consumers in real time so that users can save energy by themselves. Therefore, in this study, an air compressor was conceived to operate in three operation modes according to the air compressor's load factors: case1; on/off operation at 1400RPM when the load factor is not higher than 40\%, case 2; basically inverter operation when the load factor is 40 100\%, and case 3; standard ( $Y$ Delta) operation when the inverter is in trouble. In addition, the air compressor was studied to access the Internet to transmit its data to the Web server in real time so that the state of operation of the air compressor and the power consumed can be monitored and analyzed based on the collected data. The speed of the air that flows in through the inlet increases as the air passes the screw and the air flows out through the outlet. The pressure is affected by the direction of rotation and becomes the lowest at the top of the screw and becomes the highest at the bottom of the screw. When the rates of inflow, which are the most important performance of compressors were, it was shown that when the rotation ratio was lower, more fluid flowed in. When the rotation speed of the compressor was the same, the rate of inflow was shown to be higher when the screw rotation ratio was lower so that empty spaces between screws were larger. Low pressure was applied to the upper part of the compressor and high pressure was applied to the lower part of the compressor. The positions of low pressure and high pressure were determined by the direction of rotation of the screw according to the shape of the compressor.
\end{abstract}

Keywords: Air Compressor, Smart, Flow Characteristics, Pressure Distribution, Redundant Actuator

\section{Introduction}

A compressor is a mechanical device that compresses a gas or liquid to increase pressure and speed. In South Korea and overseas, there have been many study reports in diverse fields of air compressors based on small piston and screw air compressors $[1,2]$. On reviewing the distribution of electric power consumed in factory facilities in industrial settings, it can be seen that $20 \sim 35 \%$ of the electric power is consumed by air compressors. Therefore, air compressor energy saving has come to the fore as an urgent task that must be solved $[3,4]$.

The industrial world, which emits $50 \%$ of greenhouse gases in South Korea, is making efforts to reduce energy consumption voluntarily by preparing detailed plans considering

Received (October 15, 2017), Review Result (December 19, 2017), Accepted (January 18, 2018) 
characteristics by industry [5,6]. On reviewing the distribution of electric power consumed by factory facilities, it can be seen that $20-35 \%$ is consumed by air compressors[7]. Therefore, air compressor energy saving is an urgent task that must be solved. The energy policies of advanced countries are shifting from supply management to demand management. In the electricity market, charges and systems, which treat demand management resources equally with the supply capacity of power plants and induce optimum energy use or saving, have been legalized. The fields to which the energy management system (EMS) is applied include air compressors, which are used as essential power sources for industrial equipment $[8,9]$.

Existing inverter air compressors have a built-in inverter-activated single actuator. However, due to the disadvantage that the inverter takes a long maintenance time in case of inverter failure, users have avoided the use of energy efficient inverter type air compressors. Existing air compressors could not be efficiently managed because the user and the manager could not monitor the air compressors' operation status (operation, stop, failure, load, no load, and part replacement time) and power consumption in real time[10.11]. In addition, existing inverter-controlled air compressors can save energy by more than $30 \%$ compared to standard type (Y / D) compressors at a utilization rate of $60 \%$. However, they have a disadvantage that it is difficult to maintain and repair the inverter when the inverter fails and the maintenance takes a long time. In addition, thanks to the development of IT technology, smart grid products are produced in the case of many products that use electricity such as industrial boilers and room cooling/heating and lighting products. However, study reports in the field of smart grid technology are insufficient in the case of air compressors [12].

In addition, studies of redundant actuator \& smart grid high efficiency air compressors are acutely required to supply products engrafted with smart grid IT technology to inform the electric power consumed by air compressors to consumers in real time so that users can save energy by themselves. Therefore, in this study, an air compressor was conceived to operate in three operation modes according to the air compressor's load factors: case1; on/off operation at 1400RPM when the load factor is not higher than $40 \%$, case 2; basically inverter operation when the load factor is $40 \sim 100 \%$, and case 3; standard (YDelta) operation when the inverter is in trouble. In addition, the air compressor was studied to access the Internet to transmit its data to the Web server in real time so that the state of operation of the air compressor and the power consumed can be monitored and analyzed based on the collected data.

\section{Block Diagram of the Redundant Actuator \& Smart Grid Air Compressor}

\subsection{Block Diagram of the Air Compressor}

Figure 1 shows the cooling system of the air compressor. The existing air compressor technology is a system to inhale and compress the air in the atmosphere, which causes problems mainly in summer. In summer, the ambient temperature and humidity are high so that the air compressor compression efficiency is low and the discharge temperature of the compressed air is high, which are major causes of the failure of air compressors and dryers. Therefore, air compressors produce 3 to 5\% less air volumes during summer compared to winter because the temperature and humidity of the air flowing into the compressors are higher. In this study, an air compressor cooling system which can improve compression efficiency by $3 \sim 5 \%$ in summer as with winter and prevent the over-temperature phenomenon occurring due to high discharge temperatures occurring the most frequently in summer was studied.

Figure 2 shows a block diagram of the redundant actuator \& smart grid high efficiency air compressor. As shown in Figure 2, this is a redundant actuator \& smart grid high 
efficiency air compressor engrafted with smart grid IT technology to inform the electric power consumed by the air compressor to consumers in real time so that users can save energy by themselves. The redundant actuator \& smart grid high efficiency air compressor operates in three operation modes according to load factors; on/off operation at 1400RPM when the load factor is not higher than $40 \%$, basically inverter operation when the load factor is $40 \sim 100 \%$, and standard (Y-Delta) operation when the inverter is in trouble. In addition, the redundant actuator \& smart grid high efficiency air compressor was cond to access the Internet to transmit its data to the Web server in real time so that the state of operation of the air compressor and the power consumed can be monitored and analyzed based on the collected data.

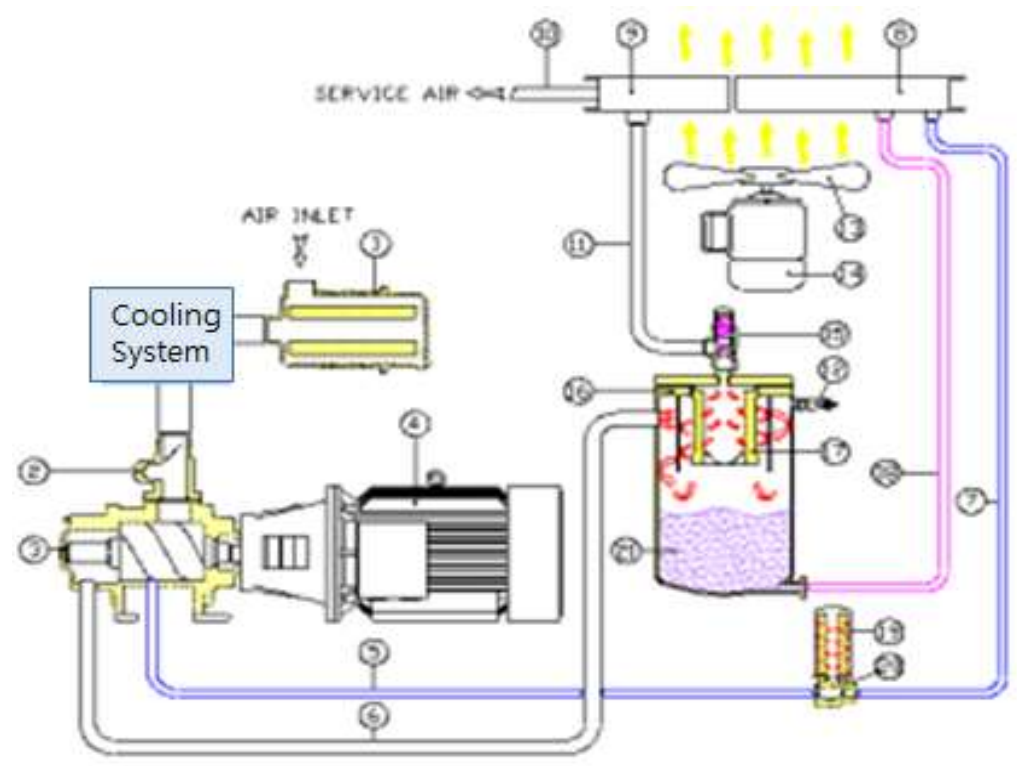

Figure 1. Air Compressor Cooling System

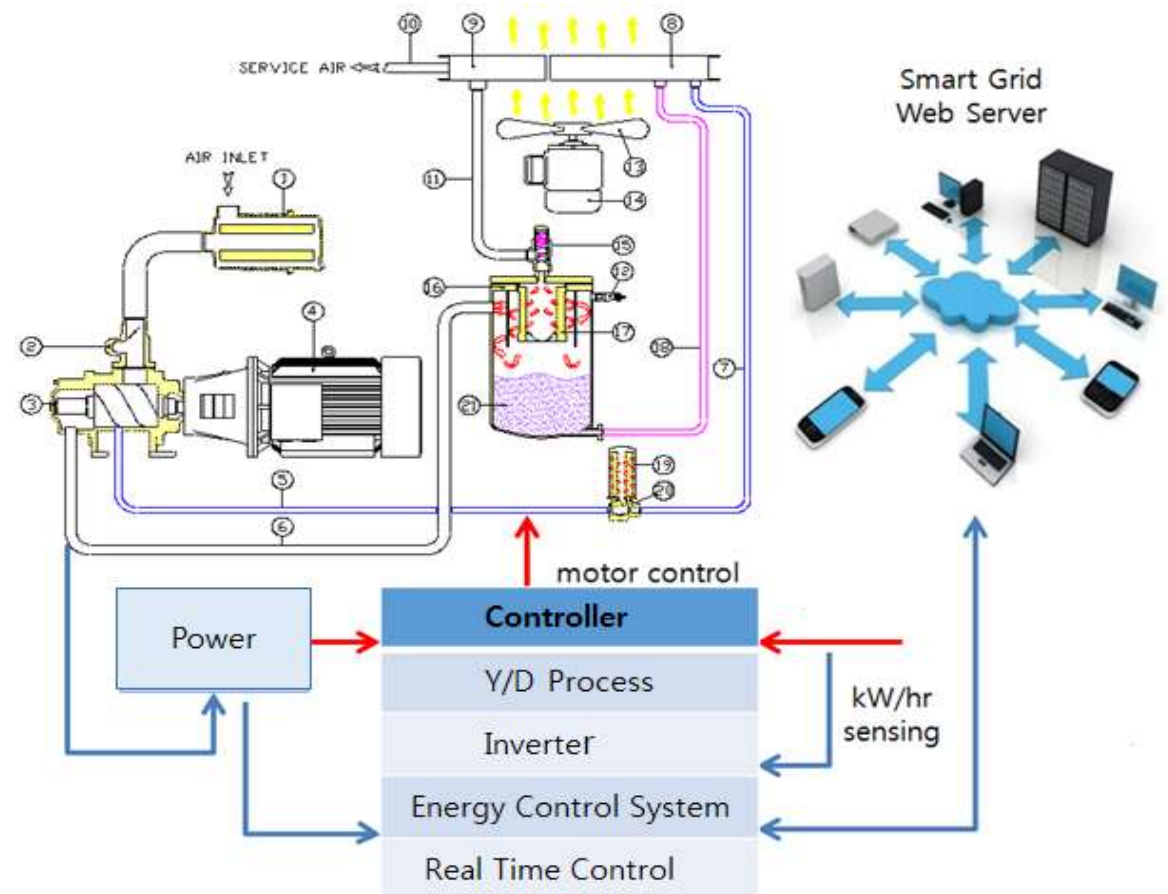

Figure 2. Apparatus of Smart Grid Air Compressor 


\subsection{Structural Shape of the Air Compressor}

The simplification of the structural shape is the most important part for flow analysis. The reasons are as follows. First, there are parts structurally necessary but are not necessary for flow analysis and unnecessary structural shapes require a very long time for flow analysis and the creation of grids but do not greatly affect actual results of flow analysis. In particular, when analyzing an abnormal flow, the time is proportional to the shape. Second, since flow shapes cannot be made when there is a problem in shape assembly, the simplification can make identifying shape problems easy. Third, problems caused by interference and contact between structural shapes can be eliminated in advance. Since simplification has advantages as such, the internal shapes were simplified as shown in Figure 3 to simplify the structural shape.

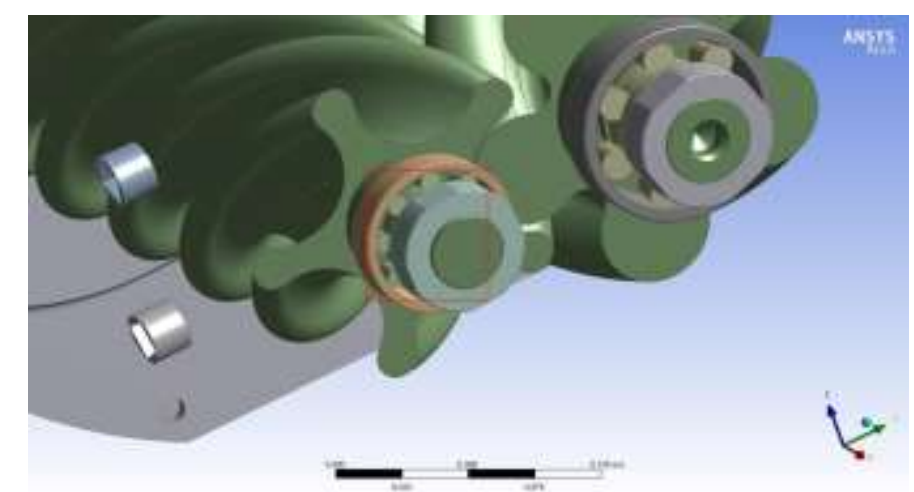

\section{Figure 3. Simplification of Internal Shapes of the Air Compressor}

\subsection{Fluid Area inside the Rotor of the Air Compressor}

The internal structure of the air compressor was set so that the fluid that entered the inside can be compressed. If the male rotor is in contact with the wall surface of the fluid area but the female rotor has a small diameter and is not in contact with the wall surface of the fluid area, the air will not be compressed at all even when the rotors rotate although the air will be moved. Therefore, the fluid area inside the rotor of the air compressor was set as shown in Figure 4.

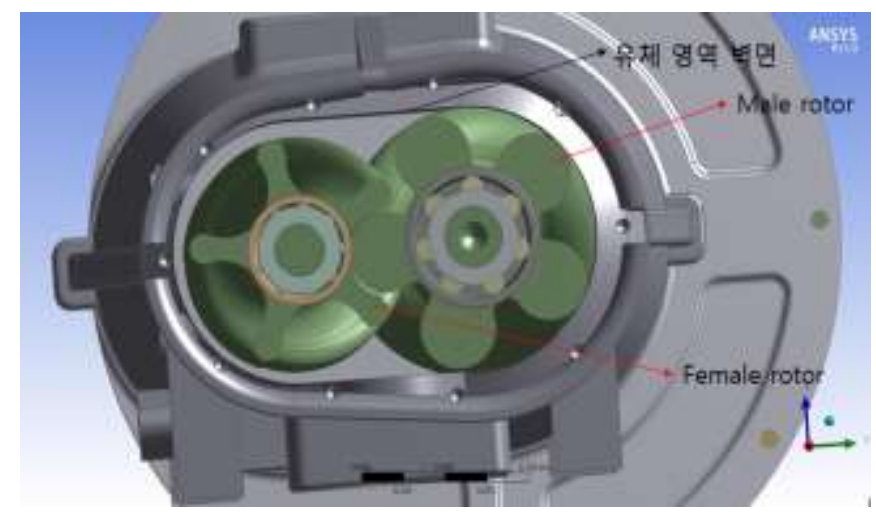

Figure 4. Fluid Area inside the Rotor of the Air Compressor

\section{Flow Analysis Modeling}

\subsection{Flow Analysis Model}

Figure 5 shows an isometric drawing of the air compressor. As shown in Figure 5, 
shapes not necessary for analysis such as chamfering in the air compressor shapes as well as all overlapping parts between shapes due to differences in tolerances were maximally removed. Screw shapes were essential not only for structural analysis but also for identification of air compression and the original shapes were maximally implemented to reduce errors in results due to changes in shapes. Based on the shapes, the flow analysis area was constructed as shown in Figure 6.

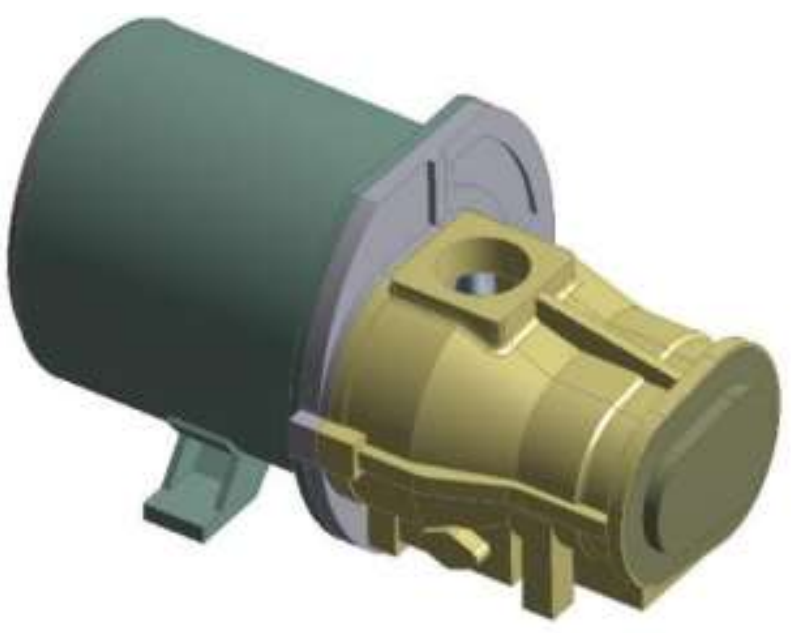

Figure 5. Isometric Drawing of the Outside of the Air Compressor

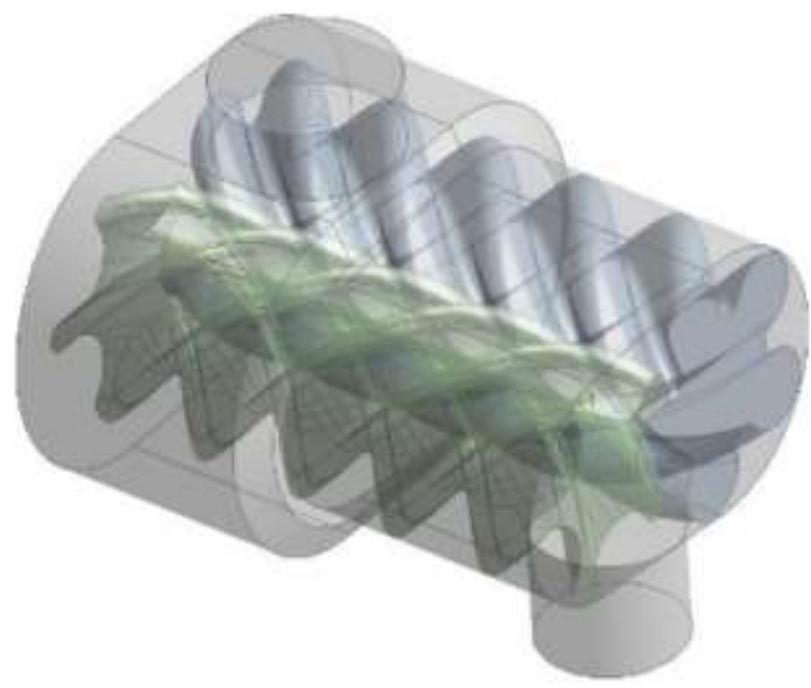

Figure 6. Shapes of Air Compressor Fluid Area and Screw

\subsection{Flow Analysis Condition}

Flow analysis was carried out with a screw rotation speed of $1800 \mathrm{rpm}$ and based on the assumption that the female and male screws were rotating in the opposite directions identically to actual screws. Non-steady state analysis was carried out. The total time of analysis was set to 0.666674 seconds, which is the time of 20 rotations and the time step for storage of the results of analysis was set to 0.00092593 seconds, which is the time for10 degree rotation. No-slip and adiabatic conditions were given to the wall. The K-e model that is generally used was used as a turbulence model. Air was applied as the fluid. The shows the locations of the inlet/outlet of the analysis domain. After extending the 
inlet and outlet area of the domain to be analyzed to be sufficiently long, the shapes of the inlet and outlet indicating the atmospheric areas were implemented so that the shapes would not affect the analysis.

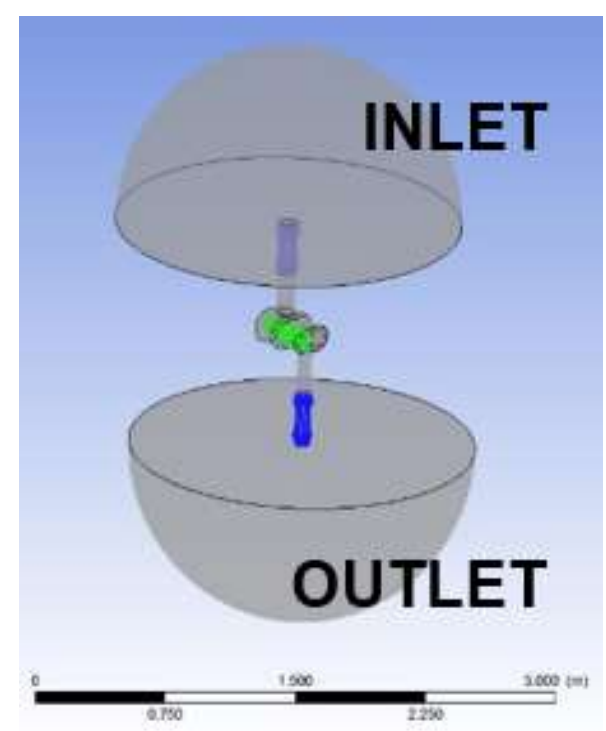

Figure 7. Boundary Condition Positions

\section{Results of Flow Analysis and Discussion}

Figure 8 shows the speed stream of a rotation ratio of 1.0. It can be seen that the speed is low when the air flows into the compressor but the speed increases as the air passes the screw. After passing the screw, speeds much higher than the speeds in the inlet area appear.

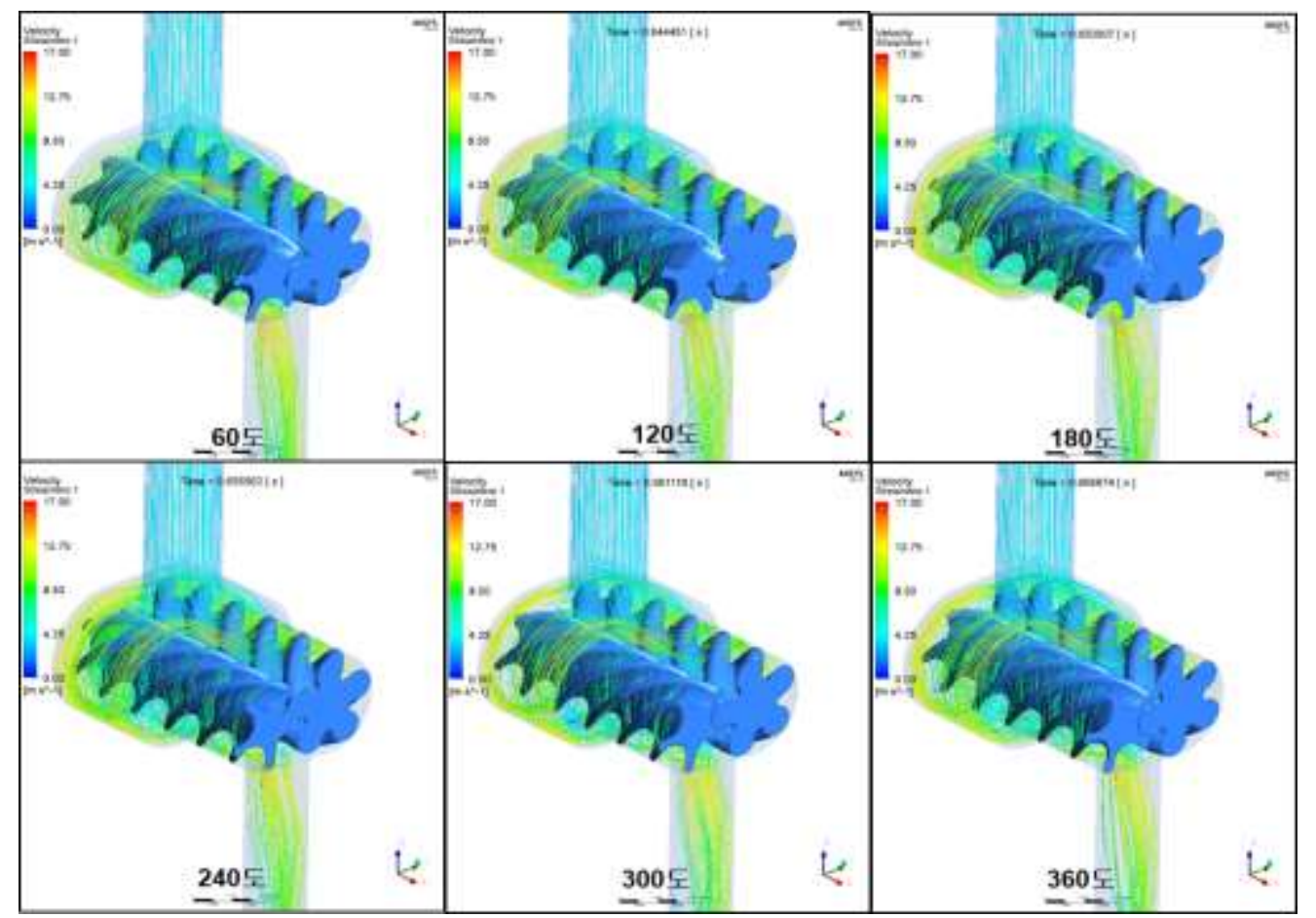

Figure 8. Speed Streams at a Rotation Ratio of 1.0 
Figure 9 shows speeds at a rotation ratio of 1.0. On checking the speed vectors on the side view, it can be seen that air flows in from the outside because of the rotation of the screw and moves along the screw. The average speed when the air flows in is shown to be $4.397 \mathrm{~m} / \mathrm{s}$, and the average speed when the air flows out is shown to ne $7.980 \mathrm{~m} / \mathrm{s}$. The speed increased by $3.583 \mathrm{~m} / \mathrm{s}$ while the air passed the screw.

Figure 10 shows the pressure at a rotation ratio of 1.0. On reviewing the pressure distribution, it can be seen that the pressure increases as the air passes the screw indicating that the air is compressed. Low pressure is applied to the upper part of the compressor and high pressure is applied to the lower part. The positions of the low pressure and the high pressure are determined by the screw rotation direction according to the shape of the compressor. The compressor's minimum pressure is $-409.91 \mathrm{~Pa}$ and the maximum pressure is $163.63 \mathrm{~Pa}$ indicating that a pressure difference of $606.54 \mathrm{~Pa}$ occurs.

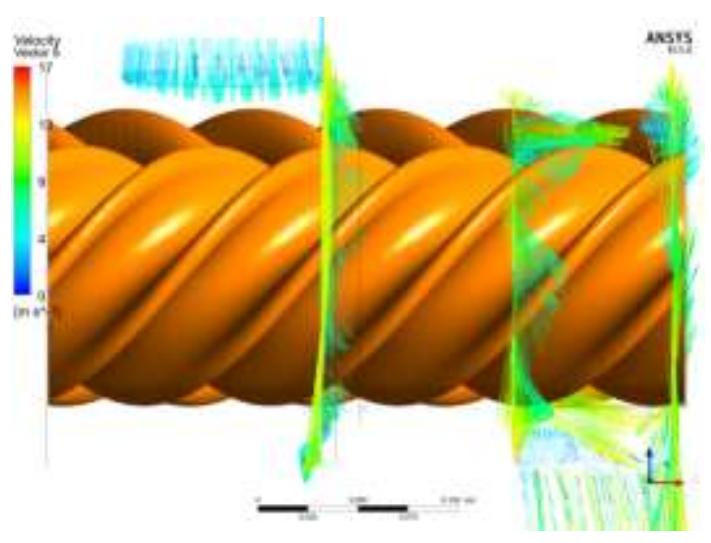

(a) Side View of Speed Vectors

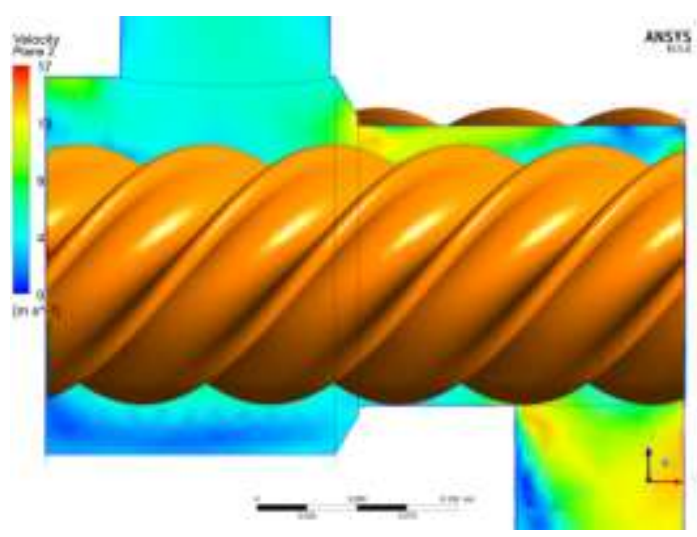

(c) Side View of Speed Distribution

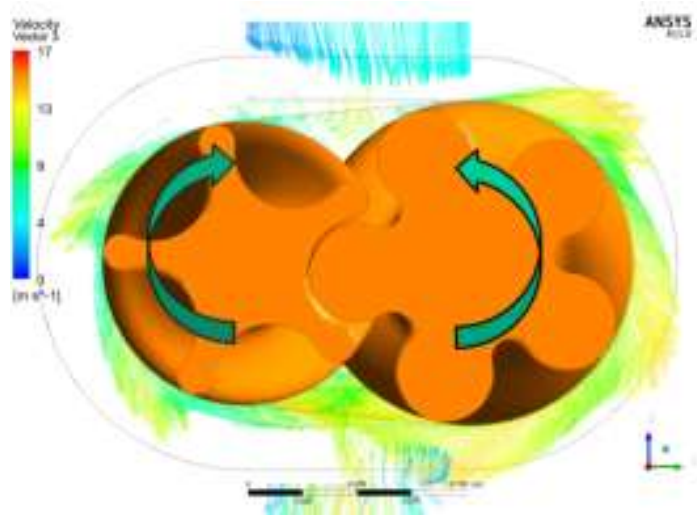

(b) Front View of Speed Vectors

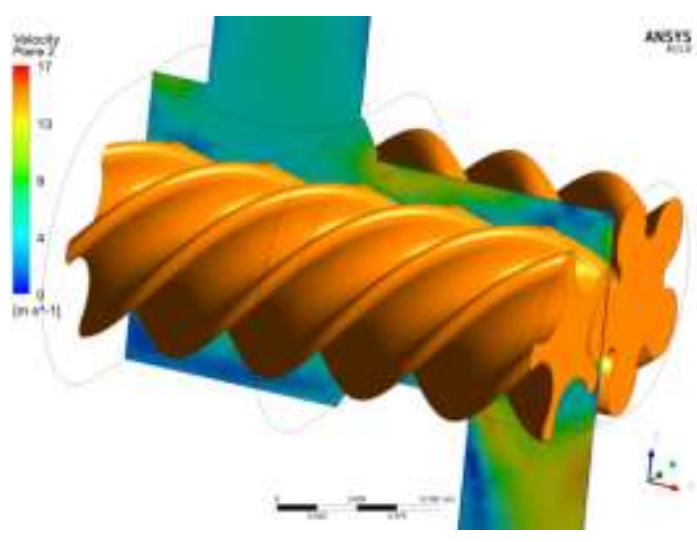

(d) Isometric Drawing of Speed Distribution

Figure 9. Speeds at a Rotation Ratio of $\mathbf{1 . 0}$ 


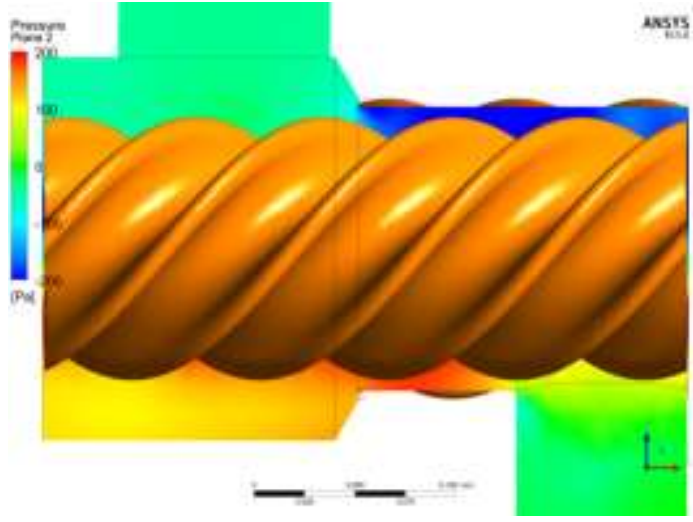

(a) Side View of Pressure Distribution

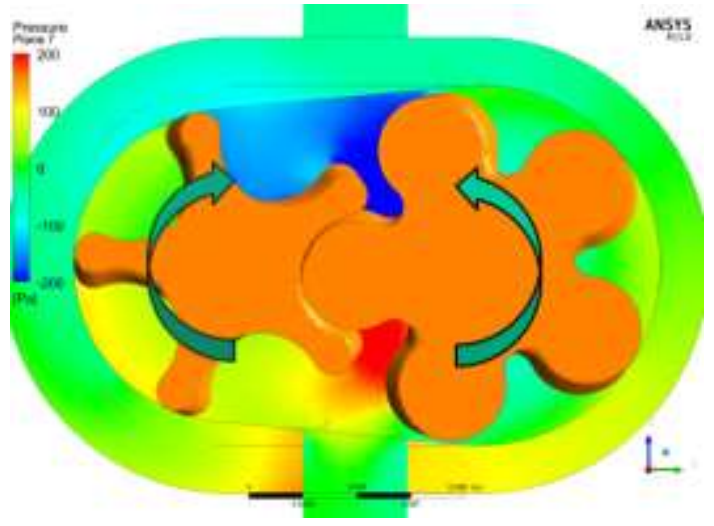

(b) Front View of Pressure Distribution

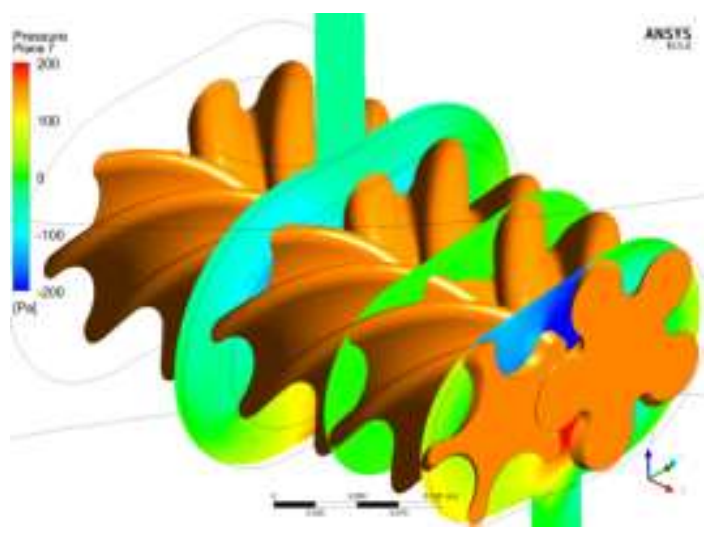

(c) Isometric Drawing of Pressure Distribution-1

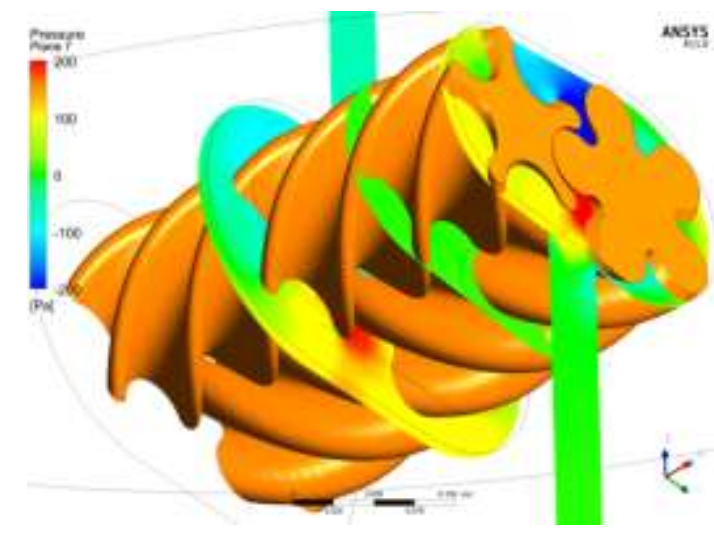

(d) Isometric Drawing of Speed Distribution-2

\section{Figure 10. Pressure at a Rotation Ratio of 1.0}

Figure 11 shows the speed stream of a rotation ratio of 1.2. It can be seen that the speed is low when the air flows into the compressor but the speed increases as the air passes the screw. After passing the screw, speeds much higher than the speeds in the inlet area appear. 


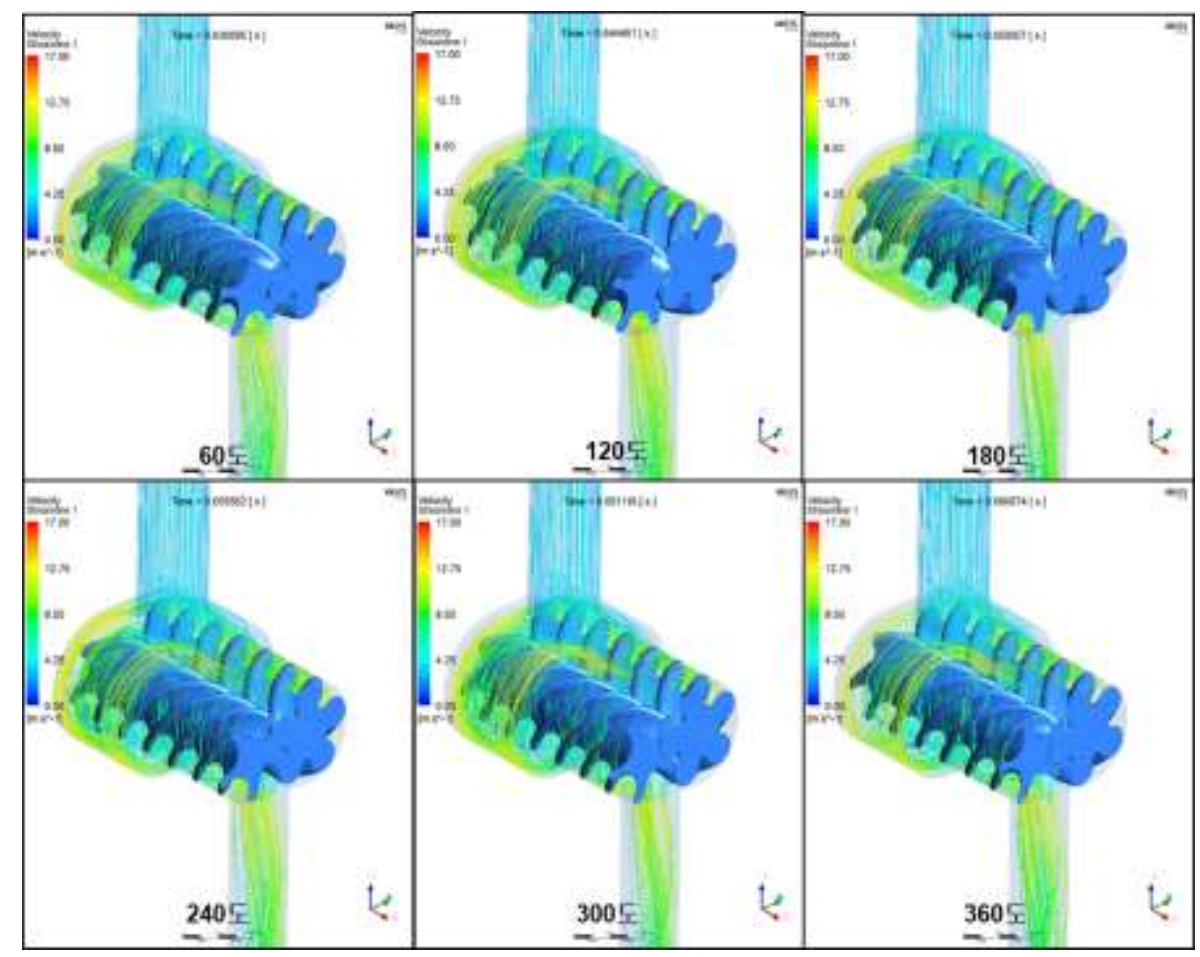

Figure 11. Speed Streams at a Rotation Ratio of $\mathbf{1 . 0}$

Figure 12 shows speeds at a rotation ratio of 1.2. On checking the speed vectors on the side view, it can be seen that air flows in from the outside because of the rotation of the screw and moves along the screw. The average speed when the air flows in is shown to be $4.178 \mathrm{~m} / \mathrm{s}$, and the average speed when the air flows out is shown to ne $7.662 \mathrm{~m} / \mathrm{s}$. The speed increased by $3.484 \mathrm{~m} / \mathrm{s}$ while the air passed the screw.

Figure 13 shows the pressure at a rotation ratio of 1.2. On reviewing the pressure distribution, it can be seen that the pressure increases as the air passes the screw indicating that the air is compressed. Low pressure is applied to the upper part of the compressor and high pressure is applied to the lower part. The positions of the low pressure and the high pressure are determined by the screw rotation direction according to the shape of the compressor. The compressor's minimum pressure is $-348.82 \mathrm{~Pa}$ and the maximum pressure is $211.39 \mathrm{~Pa}$ indicating that a pressure difference of $570.20 \mathrm{~Pa}$ occurs.

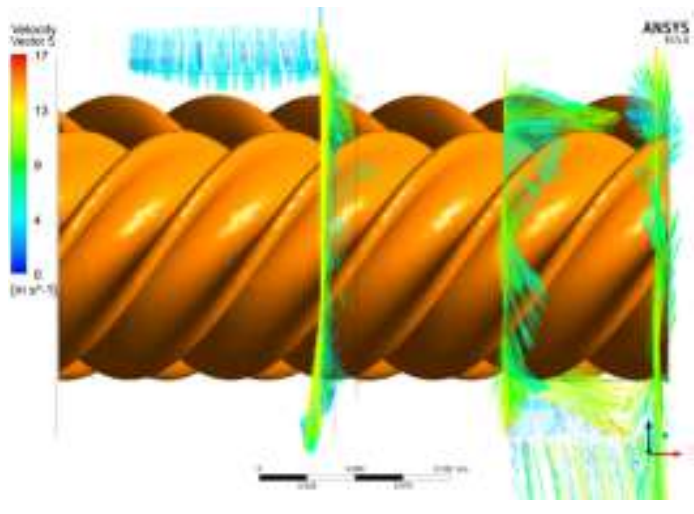

(a) Side View of Speed Vectors

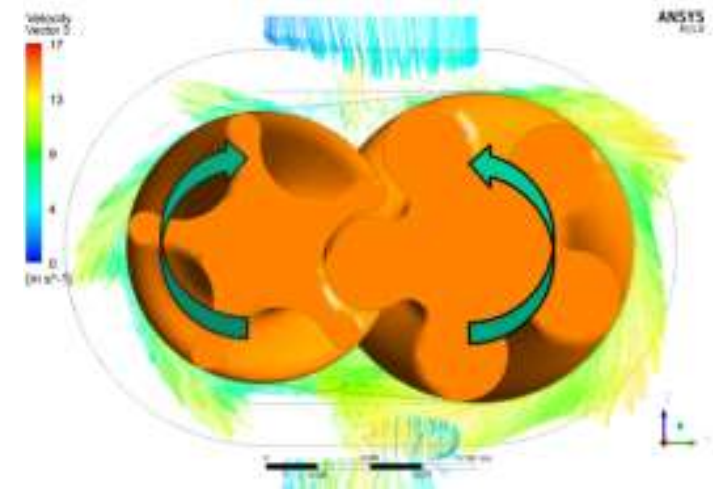

(b) Front View of Speed Vectors 


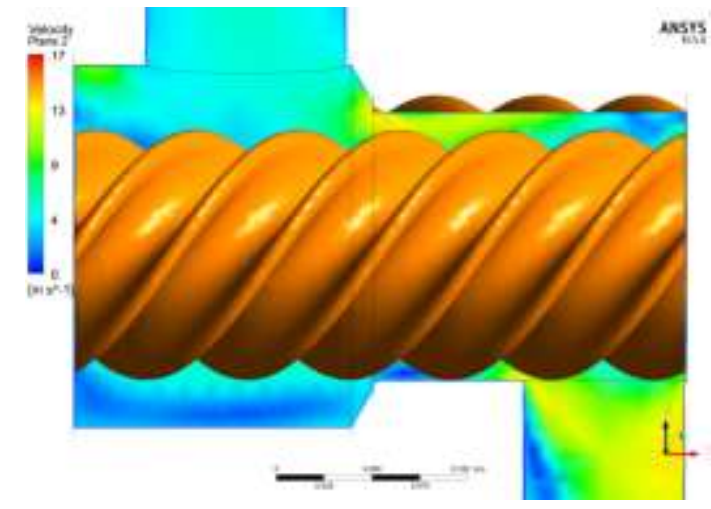

(c) Side View of Speed Distribution

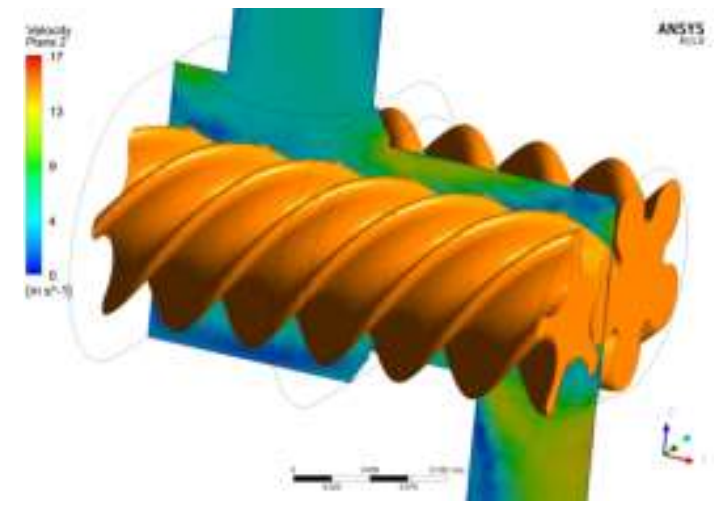

(d) Isometric Drawing pf Speed Distribution

\section{Figure 12. Speeds at a Rotation Ratio of $\mathbf{1 . 2}$}

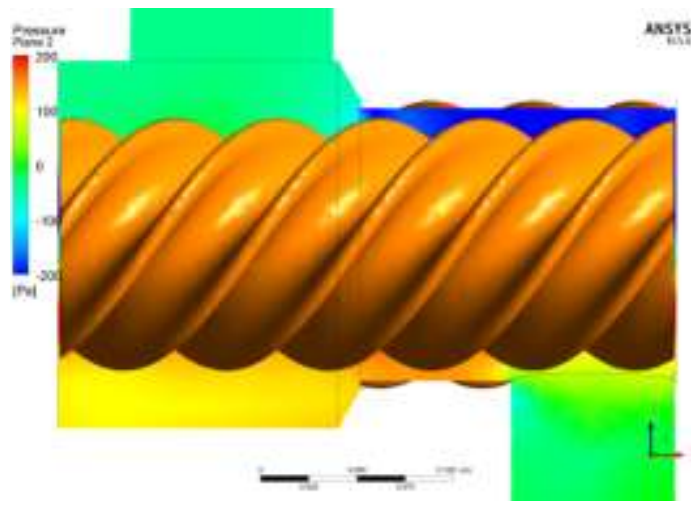

(a) Side View of Pressure Distribution

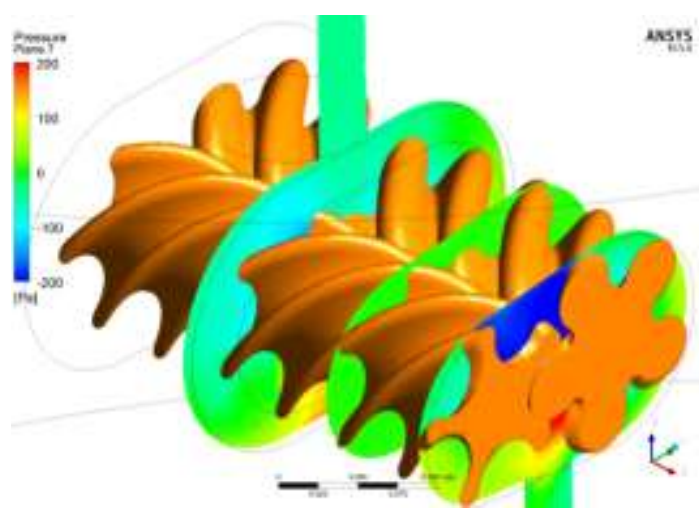

(c) Isometric Drawing of Pressure Distribution-1

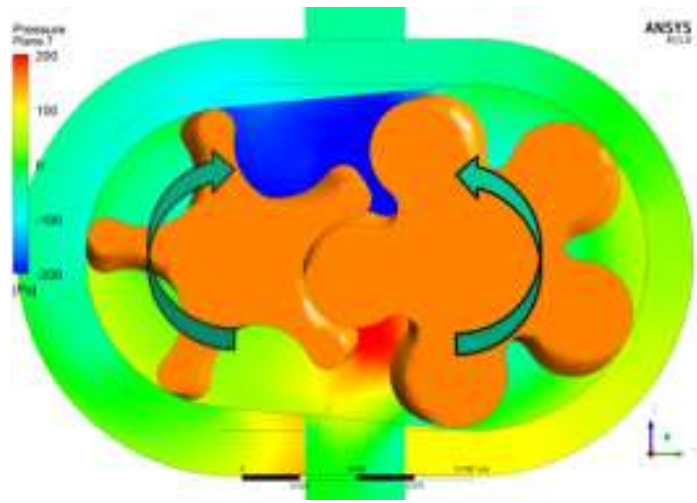

(b) Front View of Pressure Distribution

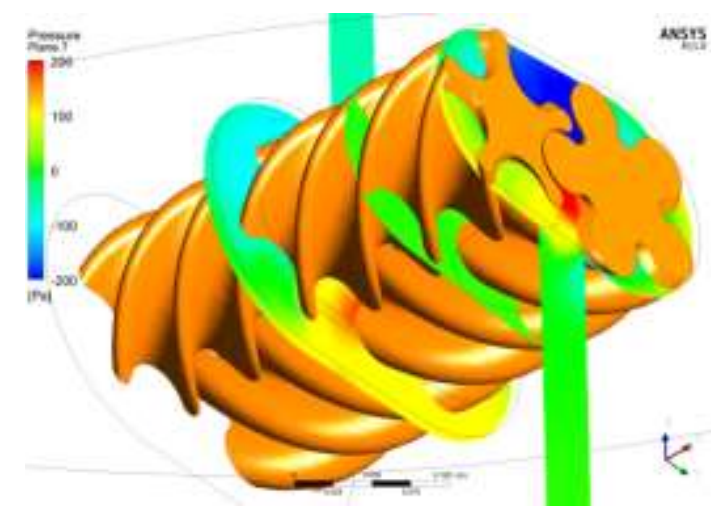

(d) Isometric Drawing of Speed Distribution-2

\section{Figure 13. Pressure at a Rotation Ratio of $\mathbf{1 . 0}$}

\section{Conclusion}

A actuator\& smart grid high efficiency air compressor that informs the electric power consumed by the air compressor to consumers in real time so that the user can save energy by himself/herself was cond by engrafting smart grid IT technology and the flow characteristics and pressure distribution of the air compressor were studied to obtain the following conclusions. 
1) The speed of the air that flows in through the inlet increases as the air passes the screw and the air flows out through the outlet. The pressure is affected by the direction of rotation and becomes the lowest at the top of the screw and becomes the highest at the bottom of the screw.

2) When the rates of inflow, which are the most important performance of compressors were, it was shown that when the rotation ratio was lower, more fluid flowed in. When the rotation speed of the compressor was the same, the rate of inflow was shown to be higher when the screw rotation ratio was lower so that empty spaces between screws were larger.

3) Low pressure was applied to the upper part of the compressor and high pressure was applied to the lower part of the compressor. The positions of low pressure and high pressure were determined by the direction of rotation of the screw according to the shape of the compressor.

\section{References}

[1] J. Watton and K. L. Franklin, "The Transient Pressure Characteristics of Positive Displacement Vane Pump", Journal of Power and Energy, vol. 204. part A, (1990), pp. 269 273.

[2] T. Nishiumi and T. Maeda, "The Relationship between Vane Motion and Chamber Pressure in a Vane Pump", Fluid Power, (1998), pp. 209 214.

[3] J. S. Jang, K. H. KimM. R. Cho and D. C. Han, "The Characteristics of Pressure Ripple in Variable Displacement Vane Pumps", Journal of Power and Energy, vol. 216 Part A, (2002), pp. 89 96.

[4] J. U. Cho, B. S. Min, E. J Lee and J. S. Nam, "Model Design by Structural Analysis of Vinyl House at Heavy Snow", Journal of the Korea Academia-Industrial cooperation Society, vol. 11, no. 8, (2010), pp. 2727-2733.

[5] J. Breribach and F. Kranzlin, Fungi of Switzerland, Boletes and Agarics, vol. 3, (1991), pp. 312.

[6] M. Lee1 and T.-W. Kim, "A Study on the Heat Sink with internal structure using Peltier Module in the Forced Convection", Journal of the Korea Academia-Industrial cooperation Society, vol. 15, no. 6, (2014), pp. 3410-3415.

[7] D. Y. Kim, J. M. Yang, J. R. Park and J. C.1 Woo, "Developing a Winder Controller for Greenhouse Winding Walls Sensing Temperature and Humidity”, Korean Institute of Intelligent Systems, (2013), pp. 209-210.

[8] J.-W. Kim1, J.-H. Lee1 and C.-H. Park, "Research of shape optimization for High-Efficiency Electronic cold modules taking into consideration thickness and thermoelectric element mounting position", Journal of the Korea Academia-Industrial cooperation Society, vol. 16, no. 12, (2015), pp. 8350-8356.

[9] K. J. Yong1, B.-C. Lim1 and S.-H. Park, "Heat Flow Analysis of Inner Groove Tube for Latent Heat Exchanger in Condensing Gas Boiler", Journal of the Korea Academia-Industrial cooperation Society, vol. 15, no. 7, (2014), pp. 4052-4056.

[10] Y. T. Kim, "A study on the three dimensional stress analysis and failure of O-ring", A Thesis for a Master, Yeungnam University, Republic of Korea, (2009).

[11] J. W. Lee,Y. H. Kim, Y. G. Kang and S. H. Lee, "Evaluation of Performance in Semi-Open Type Impeller by Duplex Stainless Material for Ballast Water Centrifugal Pump", J. of Ocean Engineering and Technology, vol. 28, no.4, (2014), pp. 345-350.

[12] Y. H. Ko, "Optimum Design of Tunnel Actuator using Finite Element Method and Response Surface Method", A Thesis for a Master, Hoseo University, Republic of Korea, (2012). 
International Journal of Advanced Science and Technology

Vol.112 (2018) 